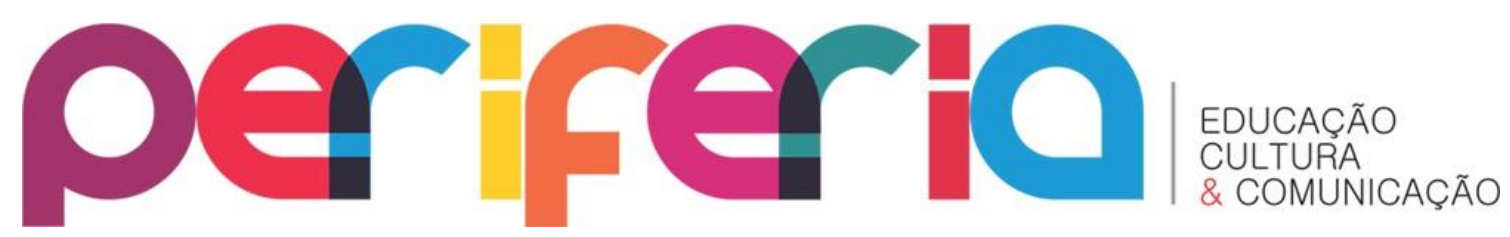

\title{
IMPRESSOES DERRIDIANAS PARA A INVESTIGAÇÃO DAS POLÍTICAS DE CURRÍCULO
}

\author{
Camila Costa Gigante ${ }^{1}$ \\ Universidade do Estado do Rio de Janeiro / CAP \\ Hugo Heleno Camilo Costa ${ }^{2}$ \\ Universidade do Estado do Rio de Janeiro / PROPED
}

\section{RESUMO}

Pautados em uma perspectiva pós-estrutural de políticas de currículo, buscamos compreender como elementos da obra de Jacques Derrida nos possibilitam investigar discursos que estão sendo produzidos no campo, através de investimentos desconstrucionistas, compreendendo a política como contingente e produzida na indecidibilidade. Por entender o pensamento de Derrida como convite a permanente deslocamento, defendemos a política curricular como texto em produção contínua, como produção discursiva marcada pela tradução desdobrada no diálogo com a alteridade, permeada por uma responsabilidade assumida nas decisões tomadas na política.

Palavras-chave: políticas de currículo; desconstrução; subjetividade; tradução.

\section{DERRIDEAN IMPRESSIONS FOR INVESTIGATION ON CURRICULUM POLICIES}

\section{ABSTRACT}

Based on a post-structural perspective of curriculum policies, we seek to understand how elements of Jacques Derrida's work enable us to investigate discourses that are being produced in the field, through deconstructionist investments, including the policy as contingent and produced in undecidability. By understanding the thought of Derrida as the permanent displacement invitation, we support the curriculum policy as text in continuous production, as discursive production marked by translation unfolded

\footnotetext{
${ }^{1}$ Professora da Universidade do Estado do Rio de Janeiro, lotada no Colégio de Aplicação, Mestre pela mesma Universidade e integrante do grupo de pesquisas Currículo, sujeitos, conhecimento e cultura. Email: camilagiga@hotmail.com

${ }^{2}$ Mestre em educação pelo PROPED/UERJ e doutorando em educação pelo mesmo programa. Professor substituto da Faculdade de Educação da UERJ. Desenvolve pesquisas na área de currículo, voltando-se para os temas: Políticas de Currículo, Ensino de Geografia, Subjetivação política, Pós-estruturalismo.
} 


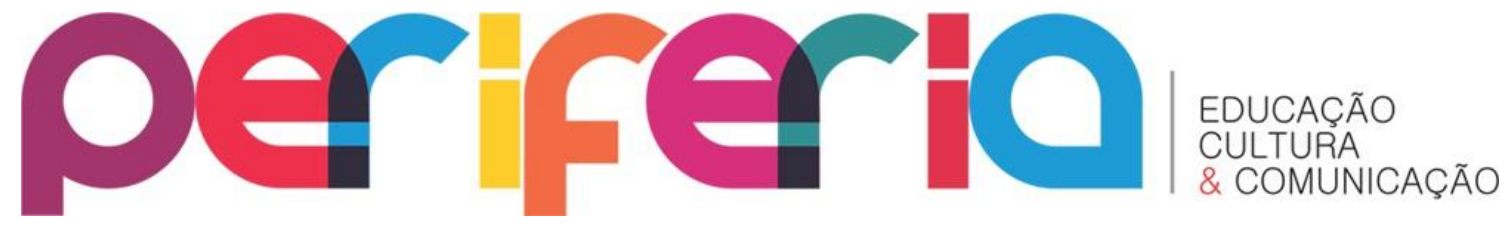

in dialogue with alterity, permeated by an assumed responsibility for contingent decisions taken in the policy.

Keywords: curriculum policies; deconstruction; subjectivity; translation. 


\section{periferio}

INTRODUÇÃO: UMA LEITURA DO PENSAMENTO PÓS-ESTRUTURAL

Começamos este texto focalizando nossa perspectiva de pós-estruturalismo e como sua compreensão é relevante para a reflexão no campo da Educação ou das Ciências Sociais e Humanas de maneira geral. Concordamos com Mendonça e Rodrigues (2014) sobre a compreensão da Ciência como estudo mais comprometido, mas isso de forma alguma é apresentado como um pensamento negativo em relação aos estudos anteriores. Esse comprometimento de/e com a significação, pelo contrário, oferece mais credibilidade ao campo, ao apontar que não existe uma busca por fundamentos únicos ou últimos para uma prática ou para uma teoria científica.

Na Filosofia, a ideia de fundamentação última é remarcada desde tentativas como a fundar a origem primeira da natureza (apresentada por Tales de Mileto, Anaximandro, por exemplo) e de construir sistemas filosóficos que pudessem dar conta de todo o saber humano na filosofia moderna (como nos trabalhos de Descartes e Hegel). No século XX, com o "giro linguístico" e a fenomenologia de Husserl e Heidegger, o debate referente à possibilidade de fundamentação se torna mais intenso (MENDONÇA; RODRIGUES, 2014). Já entre 1950 e 1960, considerações sobre fundamentação e cientificidade tornam-se mais frequentes na área das Ciências Sociais e dão força para o que se denominou como Estruturalismo (DOSSE, 2007).

O Estruturalismo defende que os termos somente possuem sentido se considerados na relação a si, e que todas as relações são interdependentes, produzindo um efeito sistêmico, segundo Saussure (PETERS, 2000). O fundamental seria compreender a estrutura enquanto algo totalizante, fundante à significação. A partir de uma crescente tensão entre fundamentação às críticas e seus limites, ganha vulto o pensamento pós-estrutural, oportunizando um projeto de crítica a perspectivas fundamentais, estruturantes, também envolvido com o nome Pós-fundacionismo (MENDONÇA; RODRIGUES, 2014, p. 28). A perspectiva pós-fundacional, associada a uma agenda genérica pós-estrutural, pode ser entendida como uma reação à simples dispersão das diferenças e também da negação da possibilidade de todo e qualquer fundamento (DE ALBA; LOPES, 2014). 


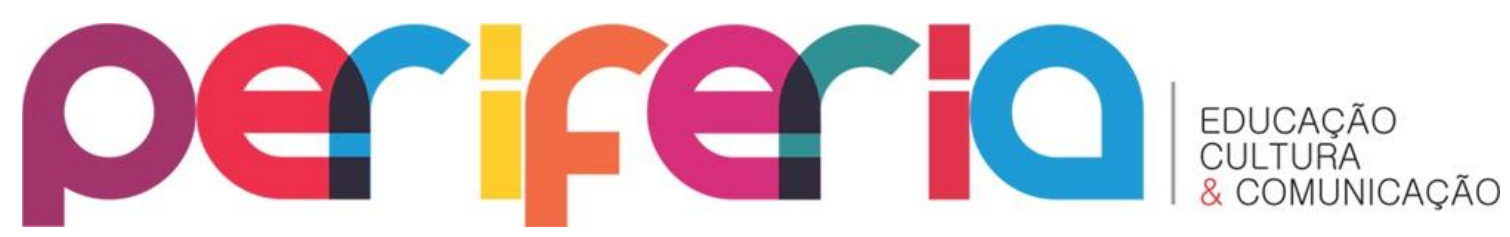

Não concordamos com a existência de um Pós-estruturalismo enquanto movimento homogêneo, mas focalizamos em seu âmbito a perspectiva da desconstrução (DERRIDA, 1992; 1998; 2004; DERRIDA; ROUDINESCO, 2004) de leituras restritivas, caras a motes estruturalistas. Consideramos também que o Pósestruturalismo não surge enquanto uma ruptura total e completa com o Estruturalismo. Pelo contrário, pensamos que retém ideias para construir e operar críticas. Focaliza a discussão epistemológica buscando a desconstrução de certas noções positivistas que defendem o Realismo como fundamento e adota essa tal postura anti ou pós-fundacionalista (MENDONÇA; RODRIGUES, 2014). Essa compreensão ganha força, principalmente, com a obra de Jacques Derrida, que privilegiamos aqui.

\section{A IMPORTÂNCIA DA DESCONSTRUÇÃO DERRIDIANA}

Para Derrida (2009), a impossibilidade de totalização de um sistema não ocorre devido aos objetos empíricos de uma sociedade serem (in)finitos ou por uma incapacidade do indivíduo limitar essa totalização. O que a ocasiona é uma falta constitutiva à própria estrutura a que julgamos nos referir, algo fixo, tornando as significações sempre contingentes, pois estão sempre expostas a um fechamento porvir. Não é, portanto, possível localizar um centro estrutural capaz de deter as substituições de significações, tornando a pluralidade de sentidos sempre aberta e admissível, possível e potente a novos sentidos, devido a não existir um fechamento final. Esta impossibilidade de significação final, esta provisoriedade substitutiva ao fundamento ou estrutura torna-se, assim, dinâmica lacerante de expectativas de estruturação sobre o significado do mundo.

Entendemos que a noção de impossibilidade do fechamento caracteriza ou margeia o pensamento da desconstrução em Derrida (2009), que não é uma propriedade a ser apreendida, não poder ser iniciada por uma consciência ou expertise. A desconstrução, para o filósofo, é um movimento atado à reiteração, à revisitação, à retomada, a busca por aprofundamento. 0 movimento 


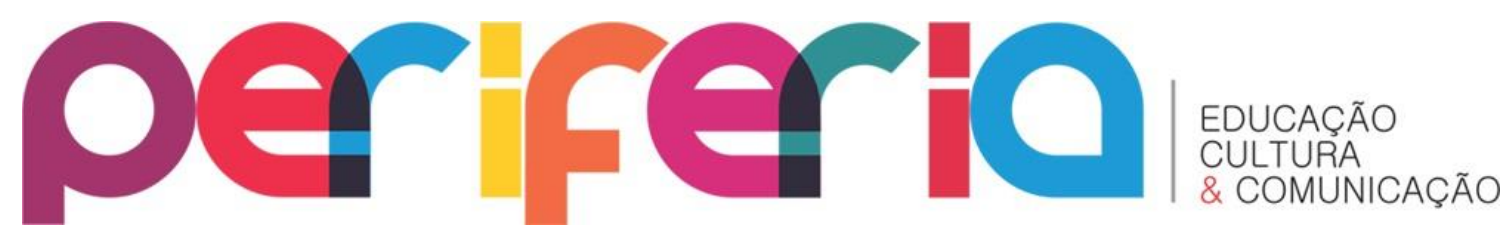

desconstrucionista sempre já esteve em operação, e isto estaria para além de um saber capaz de acioná-la como dispositivo ou técnica.

Ressalvamos a desconstrução, contundo, como não sendo sinônimo de destruição, mas de envolvimento adúltero com a própria construção. Não há, nisso, uma leitura de ruptura totalizante ou plena entre algo anteriormente dado e o atual, bem como uma desconsideração plena de suas características e reflexos.

Entendemos a experiência desconstrucionista como "uma certa experiência do impossível", por ser um pensamento que tanto é proveniente dessa impossibilidade de modelo de racionalidade quanto busca pensar sobre ela e na relação com ela (DUQUEESTRADA, 2008, p.14). A desconstrução opera com a heterogeneidade, enfocando na diferença e dissociação necessárias para que seja possível a relação com o outro desconhecido. Para isso, o rompimento com a totalidade é necessário (DUQUEESTRADA, 2008). A construção discursiva em que se constitui a ideia de sociedade, por exemplo, não deve ser compreendida como um todo homogêneo, um bloco unitário com características fixas e concretas, mas inúmeras possibilidades de significações, repletas de singularidades construídas através de processos constantes de significação dos indivíduos e do social.

Pensamos a desconstrução como sendo da ordem do impossível. Usamos este significante pela impossibilidade implícita a toda (des)ordem de significação última. São inúmeras essas impossibilidades ocasionadas pela operação desconstrutiva (DUQUE-ESTRADA, 2008). A impossibilidade se inscreve para além de qualquer reconciliação, totalidade ou centralidade do sujeito, ou da metafísica da subjetividade. Desde Heidegger (1977), é abalroada a ideia de centralidade do sujeito, na busca por criticar sua totalidade ou transcendentalidade consciente. Derrida propõe, através de uma radicalização desconstrutiva, a leitura da subjetividade para uma lógica de subjetivação.

Derrida (1992) destaca que para Heidegger ${ }^{3}$ o sujeito não pode ser reduzido a uma subjetividade fixa, pois Heidegger o pondera como fio condutor exemplar na

\footnotetext{
${ }^{3}$ Para maiores informações sobre a noção de Dasein apresentada por Heidegger, ver HEIDEGGER, 2009.
} 


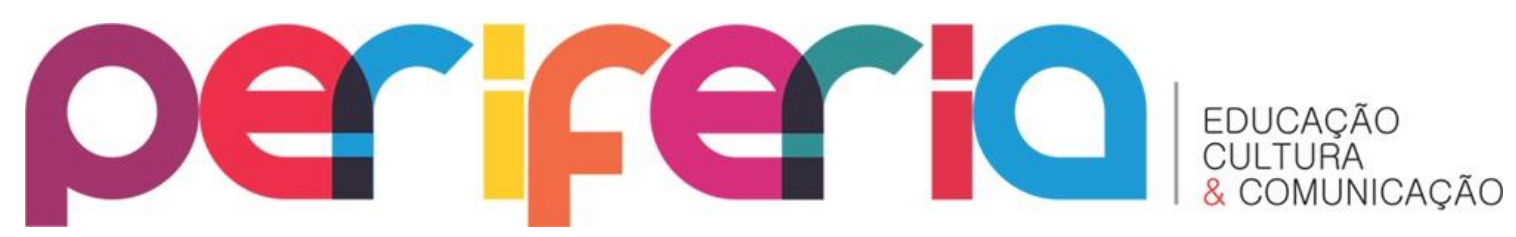

questão do ser; a dignidade máxima do ser humano estaria nele. $\mathrm{O}$ autor não oferece nenhuma definição para o significante, o aponta enquanto uma abertura para o ser. 0 ser-aí, no mundo. Ele se interessa por aquilo que todos (entendidos como público em geral) se interessam; é aquilo que todos são, mas ao mesmo tempo não consegue ser alguém específico.

Para Derrida, importa explicitar que algo denominado sujeito não pode ser definido fixamente, ainda que não defenda a "liquidação" desse termo, seu extermínio, nem opere com a ideia de que salvará ou reabilitará o que se deveria ser denominado ou determinado pelo significante. Pontua, por outra via, que o sujeito pode ser reinterpretado, reinscrito e reinstaurado (DERRIDA, 1992), mas nunca reencontrado em sua propriedade. Concordamos com o autor por acreditarmos que a leitura de sujeito pode ser deslocada, por meio da desconstrução, a um enfoque marcado por seu esvaziamento enquanto propriedade, reinterpretação, reinscrição e descentralização.

Dessa forma, poderíamos pensar que a partir da pergunta de Jean-Luc Nancy (Idem, ibidem), “Quem vem após o sujeito?”, Derrida proporia outra leitura de sujeito, pensado a partir da lógica desconstrutiva que ele apresenta. Derrida, no entanto, problematiza o "quem" da pergunta e se recusa a produzir um discurso explicativo sobre a questão, pois para ele, é preciso ser cauteloso contra uma doxa inserida na questão e que ao mesmo tempo a formula, constituindo o pressuposto de uma presença, que é ausente, a ser substituída por outra lógica estruturante/fixa. Como se pudéssemos identificar algo para denominar de "sujeito", um sentido fixo. É preciso, assim, evitar o pensamento de uma doxa - para o autor, uma opinião filosófica. O que podemos entender como uma não presença a si do sujeito. (DUQUE-ESTRADA, 2010).

Partindo destas considerações, Derrida nos possibilita pensar o sujeito para além de uma perspectiva essencialista, e mais do que isso, nos afirma que não é apropriado pensar que, com uma visão pós-fundacionista de sujeito, estaremos extinguindo-o ou que, de acordo com essa visão, ele deva ser modificado para que seja salvo. Em outras palavras, não existe um sujeito que foi destruído e que poderá vir a 


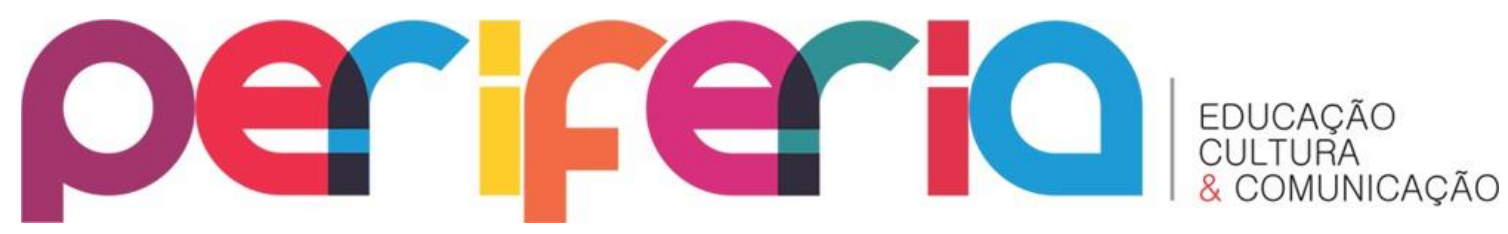

ser recuperado. A concepção de sujeito deverá ser trabalhada através da desconstrução, tendo em vista sua efemeridade e falta constitutiva.

Como seu pensamento se encontra em profundo deslocamento, pensamos que para ele não exista o/um sujeito, mas diferentes aspirações a uma condição subjetiva. Então, não interessaria uma reconfiguração normativa de uma metafísica do sujeito (assim como uma filosofia do sujeito), porque nunca nos depararíamos com apenas uma única concepção, ou algo a que possamos apreender em análise. O que pensamos funcionar para Derrida seriam problemáticas, inquietações, irritações referentes à subjetivação.

Dessa forma, ao invés de propor uma liquidação do sujeito, devemos pensar através de seu deslocamento, vê-lo como uma subjetivação deslocada, uma instância que ao mesmo tempo é fundadora e fundada, constituinte e constituída, "um 'entre' dois momentos, não se pode propriamente falar sobre O Sujeito" (DUQUE-ESTRADA, 2010, p. 8). Não que devamos deixar de usar o termo, mas devemos pensar que estaremos sempre escrevendo sobre uma instância desse sujeito, sobre um momento, um contexto, um "entre". Serão, assim, problemáticas do sujeito.

\section{DESCONSTRUÇÃO E AS POLÍTICAS CURRICULARES}

Mesmo sendo um autor que tem preocupações entendidas como caras à Filosofia, o pensamento de Derrida nos permite repensar e atribuir novas considerações teóricas ao campo da Educação. Procuramos refletir sobre algumas das principais noções de Derrida e relacioná-las a esse campo, tendo um olhar mais específico ao campo de investigações em currículo.

Neste campo, particularmente com a abordagem ao ciclo de políticas de Ball (BALL, 1994; BALL; BOWE, 1992; BALL; BOWE; GOLD, 1992), há diferentes investimentos na tentativa de romper com a verticalidade de leitura sobre a produção política. Dentre possibilidades, a proposição de Stephen Ball caracteriza um ferramental interpretativo que visa projetar a produção política através de um ciclo contínuo e incessante de escritas e reescritas, marcadas nos envolvimentos de 


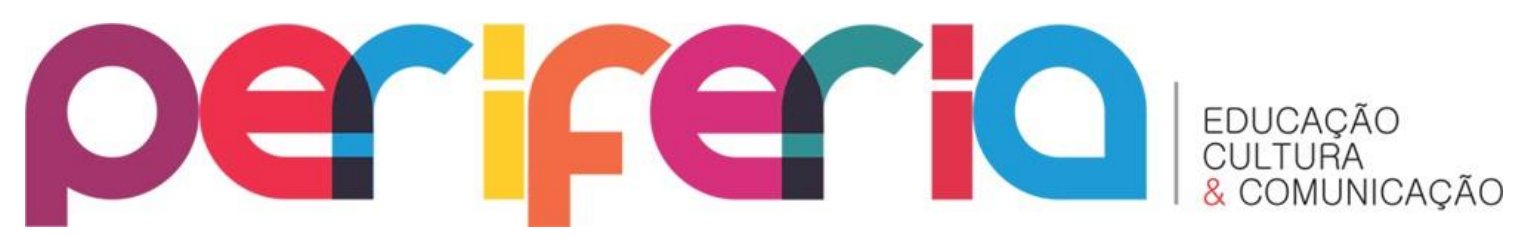

diferentes atores sociais, em diferentes espaços-tempos de poder. O autor define, desde seus trabalhos iniciais, três contextos primordiais (contexto de influência, da prática e de produção de textos), marcados por distintas formas de atuação, tramadas em uma dinâmica cíclica contínua ${ }^{4}$.

Tal abordagem ressalta processos micropolíticos, bem como a ação dos profissionais que lidam com as políticas em uma perspectiva local, em detrimento de uma perspectiva de poder hierarquizado na análise das políticas, de cima para baixo ou o inverso. Destacamos em Ball, particularmente nos textos mencionados acima, a busca pela articulação entre os processos macro e micro, de maneira que não exclua os indivíduos e grupos sociais envolvidos nos processos de produção das políticas.

No cerne da abordagem do autor encontra-se a noção de recontextualização, repensada a partir dos estudos de Bernstein (1998). Nesta perspectiva, a partir do momento em que ocorre uma migração de textos e discursos de um contexto a outro, é possibilitada uma maior apropriação e (re)interpretação de alguns sentidos por processos de recontextualização que produzem híbridos culturais (LOPES; OLIVEIRA, 2011). “É a partir da ideia de uma mistura de lógicas globais, locais e distantes, sempre recontextualizadas, que o hibridismo se configura" (LOPES, 2005, p. 56). As reinterpretações textuais são possíveis graças à pluralidade de leitores e leituras. Entretanto, a partir do momento em que textos se encontram permeados por contextos, certos sentidos hegemônicos em circulação, podemos pensar que o caminho de um contexto a outro poderá vir a gerar deformações e perdas de sentidos.

A noção de hibridismo assinala o papel do social que a cultura vem a desempenhar, não possibilitando uma completa fixidez de sujeitos específicos com tarefas já concebidas em determinados contextos. Dessa forma, acreditamos que a impossibilidade de operar com uma única concepção de sujeito, já mencionada anteriormente, é permeada, entre outras influências, pela cultura em que os indivíduos estão inseridos.

\footnotetext{
${ }^{4}$ Mesmo defendendo a existência de grupos distintos, também criticamos o ciclo de políticas quanto a esse aspecto, por acreditar que existem sujeitos e grupos sociais que se encontram participando ativamente em mais de um desses contextos de produções das políticas, concomitantemente.
} 


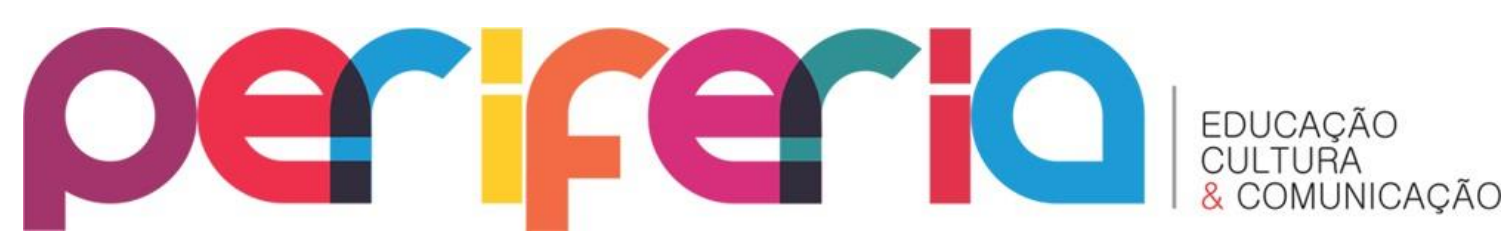

Compreendemos que nas políticas a produção de sentidos não tem origem em um contexto ou arena específicos, nem são produzidos por apenas por um grupo de atores sociais privilegiados e nem podem ser fixos ou finalizados. Os sentidos encontram-se em constante transformação e deslocamento, deslizando e gerando múltiplas interpretações. Compreendemos as políticas curriculares, bem como o social $^{5}$, como produções discursivas (LOPES; MACEDO, 2011), em que toda significação se encontra permeada pelo discurso. Quando mencionamos que o pensamento de Derrida encontra-se em "profundo deslocamento", pensamos que toda atribuição de sentidos desconstruídos é permeada pela linguagem.

Compreendendo que discurso faz referência a toda e qualquer produção de sentidos, sendo a extensão de toda linguagem possível como produção simbólica (LOPES; CUNHA; COSTA, 2013), pensamos as políticas curriculares enquanto produções discursivas. Seguindo essa perspectiva, entendemos a noção de tradução ${ }^{6}$ - pensada nos estudos derridianos - como possibilidade para entender as dinâmicas produtoras da política curricular para além da ideia de recontextualização por hibridismo. Enquanto a última concepção pondera uma representação que é própria da linguagem, sem a preocupação em problematizar o caráter não-transparente e impossível de ser compreendido da/na representação (LOPES; CUNHA; COSTA, 2013), a alternativa derridiana enfatiza a produção sempre contingente de sentidos. Derrida (2008) apresenta uma perspectiva para além do dualismo de estar e lidar no/com o mundo, de conceber onde começa e termina um contexto e, ainda, quando são iniciados processos de tradução. A linguagem seria um meio opaco no qual só se opera via tradução (LOPES; CUNHA; COSTA, 2013).

O que não nos retira responsabilidade, pois o autor pontua que em toda tradução deve haver uma preocupação ética com o outro, com a sua alteridade. Uma certa hospitalidade, também mencionada por ele como responsabilidade - uma

\footnotetext{
${ }^{5}$ O social, para Derrida, é compreendido como retoricidade. (DERRIDA, 2008)

${ }^{6}$ Apesar de Ball (BALL et al., 2011, 2012) compreender as transferências nas políticas com base em uma sociologia da tradução, ainda apresentam limitações como interpretação e tradução, entre outros aspectos. Para maiores informações, ler as obras.
} 


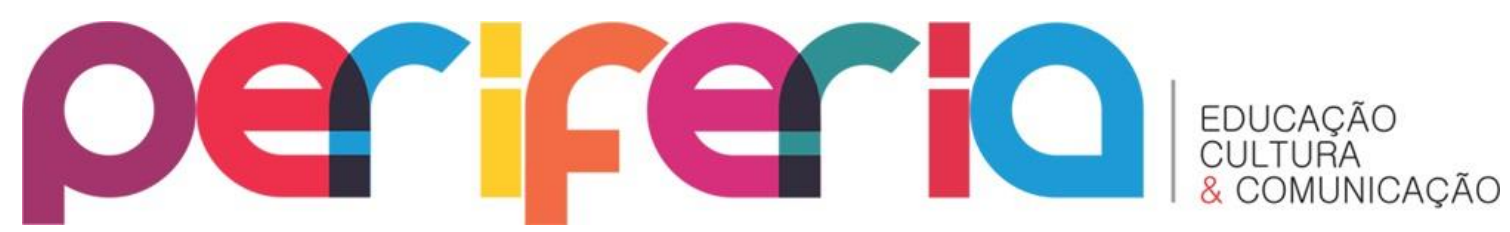

hospitalidade hostil para com o outro (SKLIAR, 2005), a qual e sobre a qual sempre responderemos. Deve ser uma hospitalidade e hostil, ao mesmo tempo, por considerar o outro enquanto estrangeiro, enquanto alteridade, estranhamento, mas buscado para si, para responder. A contabilização de tal ideia às investigações nos convidam a ter em conta que as políticas de currículo podem ser pensadas na relação com um outro que, como a subjetivação derridiana, não pode ser apreendido por uma consciência como objeto de saber. Pensar o outro, nesse caso, não só tendo em conta os efeitos que se supõe ou busca atingir, mas, principalmente, tudo aquilo a que se expõe ao decidir e que será necessário, desde sempre, responder.

Consideramos a tradução como via importante ao estudo sobre currículo e política de currículo, particularmente por possibilitar o questionamento à noção de representação fixa e plena, assinalando para que o caráter produtivo de toda prática não consiste em projeções de sentidos ou verdades coerentes, mas são produções contingentes, marcada pela emergência do pleito, da demanda, da busca pelo controle da significação. As políticas podem ser pensadas, por estas vias, como mobilizadas por discursos que sempre estarão sujeitos à traição do e pelo outro, em outro contexto, que não se pode controlar. Nelas, "múltiplos contextos são produzidos, porque múltiplos processos de significação se desenvolvem e neles a tradução opera sem cessar" (LOPES; CUNHA; COSTA, 2013, p. 398), nesse caso, já extrapolando uma perspectiva distintiva a que convida Ball quando define contextos específicos.

Com relação à alteridade, perspectiva de importância para a investigação nas políticas curriculares, ela remete ao outro enquanto relação de possibilidade. É importante que se respeite e afirme as diferenças que julgamos distinguir no outro, para que se invista na compreensão do outro como outro, não como 'eu', como propriedade. Toda relação é assim, com a alteridade. E essa alteridade dá bojo à ideia de différance (DUQUE- ESTRADA, 2002).

Para Derrida (2011), a différance é dinâmica é disseminadora, é continuamente outra. Pensamos que esta concepção nos auxilia a compreender o processo de diferenciação para além de limites ou critérios lógicos pré-estabelecidos, ajuda a 


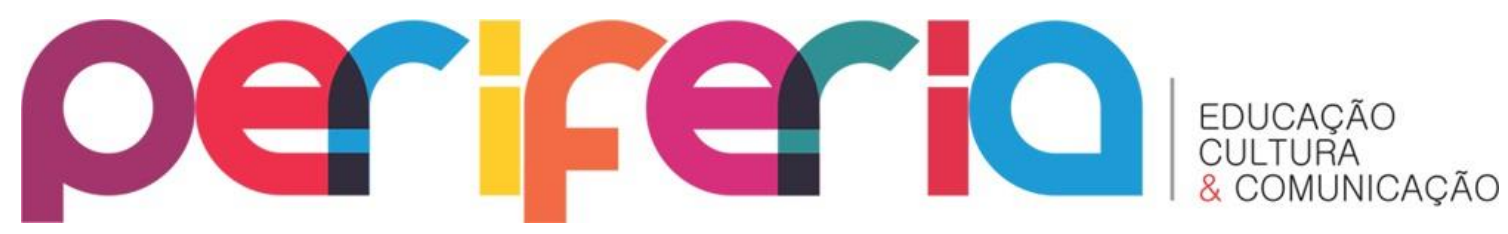

pensar o outro como não podendo ser coagido ou constrangido a pertencer a determinada classe, categoria, lacuna ou segmento fixo. A différance seria a vida no traço, a alteração na suplementação da escrita (DERRIDA, 1991), uma relação entre presença/ausência, um movimento de diferir incessante na relação com o texto em que se constitui o mundo (DERRIDA, 2001).

Como a différance não é dialética, não é interessante concebê-la em termos fixos ou polissêmicos, uma distinção ou em uma relação de dualidades. Nada, segundo Derrida (2001) escapa ao seu jogo, nem ela mesma (SKLIAR, 2005). Dessa forma, não somos/encontramos/lidamos com isto ou aquilo, mas toda menção, ao que quer que se volte, já incide em adulteração, suplementação, traição a um suposto original (um dado do que se pode chamar por cultura, uma condição social, um conteúdo de conhecimento, uma identificação, um texto). Podemos ser isto $e$ aquilo, antes isto do que aquilo, podemos não ser isto nem aquilo, mas uma terceira opção, de acordo com as situações e urgências (DERRIDA; ROUDINESCO, 2004). Nas políticas curriculares, consideramos potente a perspectiva diferencial como indício a um envolvimento com uma crítica radical, tendo em vista um horizonte de oposição defesas pautadas em binarismos, ao estancamento de verdades, à substituição prevista de afirmações por outras. Isto nos possibilita pensar que não basta assumir ou definir posições "contra" ou "a favor" em dada investigação sobre a política, ou mesmo defender interpretações e/ou desdobramentos dados por qualquer que seja a identificação em foco. Importa, por outro lado, a leitura de que o movimento diferencial inscreve a ideia de que não há possibilidade de controle ou contenção àquilo que julgamos tratar, mas que tudo o que se faz, na relação com nossos objetos de investigação, está limitado a um investimento na política, é caracterizado por formas de intervenção, por responsabilização, e também pela impossibilidade de definição ou limitação interpretativa. O investimento oportuniza intervenção ao tempo em que também nos limita em qualquer expectativa de poder controlar algo.

Com isto, não supomos possibilidades de abandono da política e/ou que devemos deixar de considerar também que decisões políticas estão constantemente 


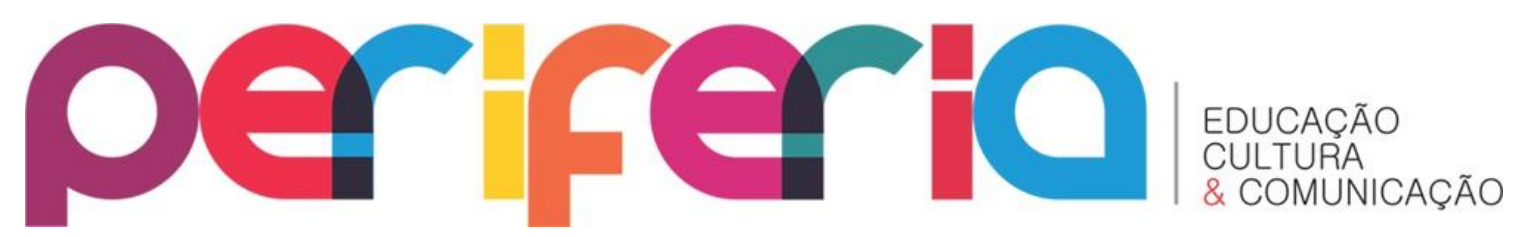

sendo permeadas e alteradas nos jogos de poder (LOPES; MACEDO, 2011), mas colocamos em questão que independente de supormos plenitude à intenção da ação política, a lemos como incapaz de funcionar plenamente e, ainda, que simultaneamente todo investimento está exposto à crítica em seus possíveis desdobramentos.

Com esta possibilidade teórica, entendemos que todo processo político, incluindo os processos das políticas curriculares educacionais, se dá no terreno do indecidível. A política curricular pode ser entendida dessa forma por considerarmos que nunca será possível um fechamento pleno e conclusivo, por mais que haja forças muito incisivas para que isto ocorra. A esse respeito, Derrida (DERRIDA; ROUDINESCO, 2004) nos propõe a ideia de uma agência interrogativa, responsável por revisar certas práticas discursivas com uma responsabilidade ética que não prevê fechamentos discursivos absolutos. Não deve haver uma "incorporação cega", mas sim uma possibilidade de fragilidade temporária, a instabilização possível em um processo desconstrutivo.

O processo político deve ser entendido como o momento do não saber, do imprevisível, de decidir de forma indecidível. É necessário compreender a produção das políticas curriculares como possibilidade não-essencial, não fundamentada ainda que se julgue apoiar algo na decisão pelo envolvimento nela. Importa pensar a responsabilidade na/da/sobre a interpretação, interrogação, sempre operando no terreno do indecidível. Dessa forma, não cabe escolher entre unidade e multiplicidade, entre certo e o errado, mas devemos operar sempre com a heterogeneidade, com a diferença, dissociação, différance, relação com o outro (DUQUE-ESTRADA, 2008), com a negociação que sempre envolve a alteridade. O que rompe com a totalidade e se torna condição para que a relação com o outro seja possível, embora nunca transparente.

Derrida não fala de uma reapropriação de formas e conceitos, mas traz a noção de ex-apropriação. Diz que é sempre uma questão do traço (uma passagem, um "estar entre", uma condição de transição. O traço não é ausência, mas também não é 


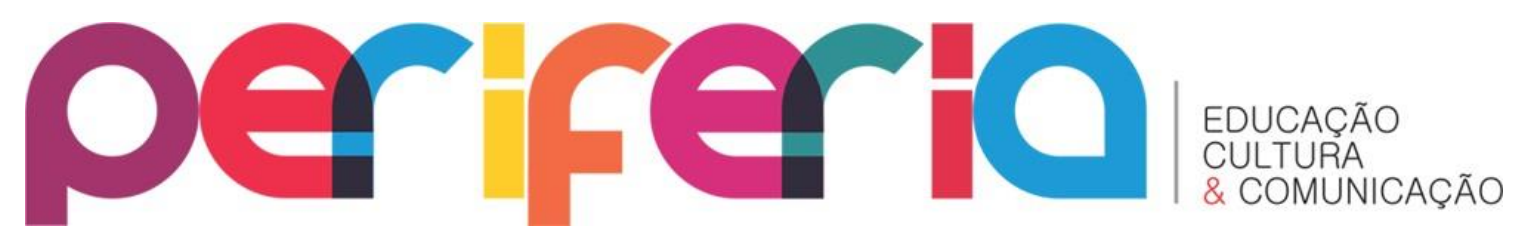

presença), mas também de iterabilidade, significando que a ex-apropriação não pode ser estabilizada na forma de um sujeito; é algo externo a ele, uma questão de alteridade. É impossível a apropriação ou ex-apropriação de algo que nunca existiu. A ex-apropriação não se encerra ou se totaliza. Não é um limite ou apenas o oposto ao infinito, mas supõe uma certa irredutibilidade da relação com o outro (DERRIDA, 1992).

Com essa discussão, retomamos à questão do sujeito, mas assumindo as possibilidades de remeter a este nome como subjetivação, como uma tentativa de fechamento das discussões apresentadas até aqui. Entendemos que as políticas curriculares devem possibilitar pensar a cultura através da noção de diferença, pois é reiterando as diferenças do outro que nos constituímos enquanto tal. Entretanto, essa constituição é sempre marcada pela provisoriedade, pela incerteza e precariedade das afirmações. Apesar da identidade ter que se auto-diferenciar, é através da possibilidade dessa diferença que se percebe o outro, dando abertura para a constituição - provisória - de uma outra identidade. Isso é o que previne o totalitarismo, o egocentrismo. Apesar de afetar uma estrutura de identidade, essa impossibilidade é que permite o diálogo com o outro, e isso que possibilita assumir responsabilidade e tomar decisões no terreno indecidível (DUQUE-ESTRADA, 2008) da linguagem, da textualização, da política curricular.

Com essa ideia de identidade, precária e contingencialmente constituída, optamos por pensar com Lopes e Macedo (2011) em processos de subjetivação. Cremos que a possibilidade de operar com uma ideia diferencial, que marca uma dinâmica de subjetivação, seja interessante à investigação no campo das políticas de currículo. Nesse caso, importa que a concepção dos atores sociais, pensados em associação com os contextos do ciclo de políticas de Ball, seja pensada como constituindo momentos de subjetivações políticas que os extrapolam. A atenção a esta ressalva consiste na diferenciação entre as ideias de atores sociais, como pessoas envolvidas em dado envolvimento social, e subjetivação, que aspira destacar processos de significação que estariam para além de pessoas ou identificações fixas. A 


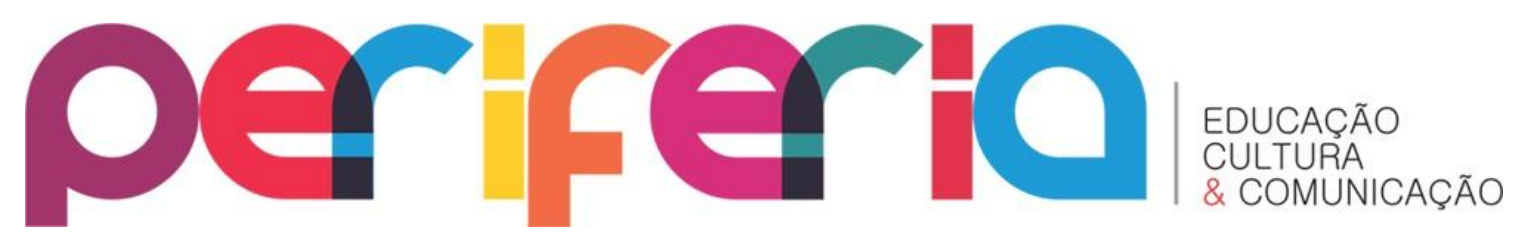

subjetivação seria constituída discursivamente, com toda marcação contingencial e provisória, nas articulações mobilizadas pelos sentidos colocados em circulação nos pleitos de atores sociais, como, por exemplo, podemos ler a atuação organizada de profissionais através de associações, partidos políticos, sindicatos, mas também em agremiações outras que, frente a determinado desafio, oportunize a que diferentes atores se vejam solidarizados.

\section{CONSIDERAÇÕES PROVISÓRIAS}

Com a discussão desenvolvida até aqui defendemos, a partir do pensamento derridiano, que a abordagem à subjetivação incide na compreensão de seu descentramento, de sua impropriedade, da impossibilidade de uma identidade estável. Neste estudo, optamos por apresentar aspectos da obra de Jacques Derrida, pinçando elementos de sua produção filosófica, com intuito de destacar possibilidades interpretativas à desconstrução com vistas a argumentos centrais da investigação em políticas de currículo, tal como o sujeito. Cremos ser importante investir nessa perspectiva, principalmente para compreender a política curricular como mobilizada na indecidibilidade.

Entendemos que a questão da ampliação da subjetividade para uma lógica de processos de subjetivação nos ajuda a pensar na ideia de identidade como sendo precária e contingencialmente constituída, o que possibilita atentarmos para o caráter fluido de toda afirmação, identificação, na política. O sujeito, para Derrida (1992) é porvir, um rastro, um traço, uma irrupção contingente, que não se pode encontrar "de fato" ou controlar. O conceito ocidental de sujeito, segundo o filósofo, é calculador, já é instaurado por um horizonte prévio que o limita, embasa.

Consideramos, neste texto, que a obra desconstrutiva de Jacques Derrida nos possibilita pensar para além de uma lógica estrutural de significados. Entretanto, aqui deixamos claro que a desconstrução não é voluntária ou imposta. Não existe um momento de operação desconstrutiva. Estamos expostos e envolvidos com a/na desconstrução desde sempre, independente de uma vontade ou orientação. A 


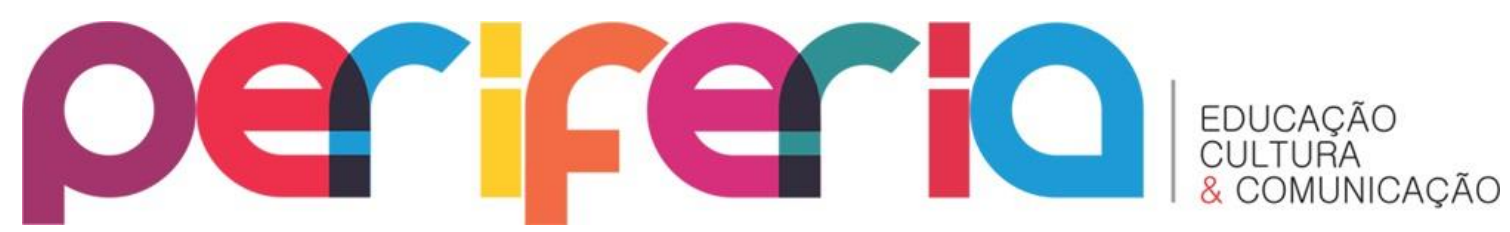

desconstrução não é uma volta ao "zero", a uma origem, mas uma abertura a novas possibilidades de significação, particularmente assinala à impossibilidade de seu controle. Tampouco podemos pensá-la a partir de uma lógica de oposição, em que de um lado estaria a construção sendo vista como uma certa preservação/salvação e, de outro, seria uma espécie de perdição, extermínio, aniquilamento.

Compreendemos que essa é uma perspectiva interessante para compreender as políticas curriculares, não enquanto textos fixos, devendo ser aplicados a partir de uma visão verticalizada de poder. Mas enquanto produções discursivas que são traduções desdobradas no diálogo com a alteridade, criando um terreno indecidível, marcado pela différance e por respostas/responsabilizações às decisões tomadas.

\section{REFERÊNCIAS}

BERNSTEIN, B. Pedagogía, control simbólico e identidade. Madrid: Morata, 1998.

DE ALBA, Alicia; LOPES, Alice. Diálogos curriculares entre Brasil e México. Rio de Janeiro: EdUERJ, 2014.

DERRIDA, J. Margens da filosofia. Campinas, São Paulo: Papirus, 1991. . "Il fautbienmanger - entrevista com Jean-Luc Nancy". In: . Point de suspension - entretiens. Paris: Galilée, 1992. Posições. Belo Horizonte: Autêntica, 2001. . Gramatologia. São Paulo: Perspectiva, 2008.

. "A estrutura, o signo e o jogo nas ciências humanas". In: . A escritura e a diferença. São Paulo: Perspectiva, 2009, pp. 407-26. ; ROUDINESCO, E. De que amanhã: diálogos. Rio de Janeiro: Jorge Zahar Ed., 2004.

DOSSE, F. História do estruturalismo: o campo do signo - 1945/1966. Bauru: Edusc, 2007.

DUQUE-ESTRADA, P. Derrida e a escritura. In: (Org.). Às margens - a propósito de Derrida. Rio de Janeiro: Ed. PUC-Rio; São Paulo: Loyola, 2002, p.11. 


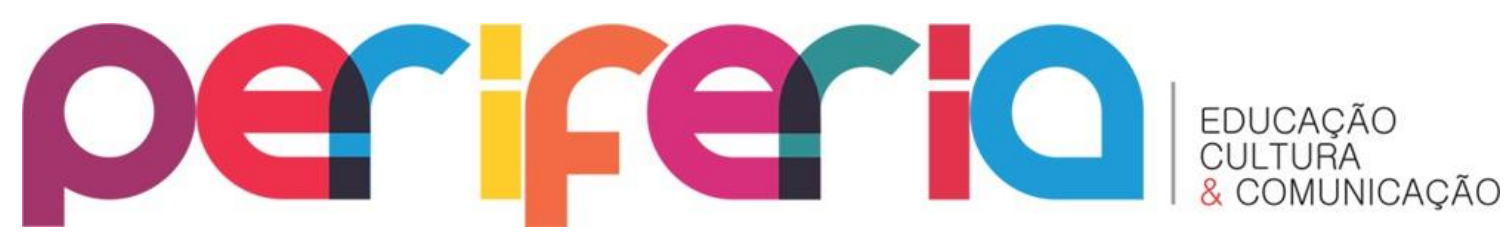

. Sobretudo... o perdão. (im)possibilidade, alteridade, afirmação. In:

(Org.) Espectros de Derrida. Rio de Janeiro; NAU Editora, 2008, pp. 13-38.

Derrida e o pensamento da desconstrução: o redimensionamento do sujeito.

Cadernos IHU ideias, ano. 8, n. 143, 2010.

HEIDEGGER, M. Ser e tempo. Petrópolis, RJ: Vozes, 4 ed, 2009.

. "The Age of the World Picture". In: LOWITT, W. (ed.). The question concerning technology and other essays, New York: Hareper \& Row, 1977.

LÉVINAS, E. Humanismo do outro homem. Petrópolis, RJ: Vozes, 1993.

LOPES, A.; CUNHA, E.; COSTA, H. Da recontextualização à tradução: investigando políticas de currículo. Currículo sem fronteiras, v. 13, n. 3, p. 392-410, set./dez. 2013.

; MACEDO, E. Teorias de currículo. São Paulo: Cortez, 2011.

; OLIVEIRA, A. A abordagem do ciclo de políticas: uma leitura pela teoria do discurso. Cadernos de educação, Pelotas, v.38, n. 19, p. 41, jan./abr. 2011.

MENDONÇA, D. de; RODRIGUES, L. Do estruturalismo ao Pós-estruturalismo: entre fundamentar e desfundamentar. In: (Org.). Pós-estruturalismo e teoria o discurso: em torno de Ernesto Laclau. Porto Alegre: EDIPUCRS, 2014.

PETERS, M. Pós-estruturalismo e filosofia da diferença (uma introdução). Belo Horizonte: Autêntica, 2000.

SKLIAR, C. Derrida e a educação. Belo Horizonte: Autêntica, 2005. 